\title{
Developing Emotional Intelligence as a key psychological resource reservoir for sustained student success
}

\author{
Authors: \\ Gina Görgens-Ekermans ${ }^{1}$ \\ Marthinus Delport ${ }^{1}$ \\ Ronel du Preez ${ }^{1}$

\section{Affiliations:} \\ ${ }^{1}$ Department of Industrial \\ Psychology, Stellenbosch \\ University, South Africa \\ Correspondence to: \\ Gina Görgens-Ekermans \\ Email: \\ ekermans@sun.ac.za \\ Postal address: \\ Private bag X1, Matieland, \\ Stellenbosch 7602, South \\ Africa

\section{Dates:} \\ Received: 23 Oct. 2014 \\ Accepted: 08 Apr. 2015 \\ Published: 10 July 2015 \\ How to cite this article: \\ Görgens-Ekermans, G., \\ Delport, M., \& Du Preez, \\ R. (2015). Developing \\ Emotional Intelligence as a \\ key psychological resource \\ reservoir for sustained \\ student success. SA Journal \\ of Industrial Psychology/SA \\ Tydskrif vir Bedryfsielkunde, \\ 41(1), Art. \#1251, 13 pages. \\ http://dx.doi.org/10.4102/ \\ sajip.v41i1.1251

\section{Copyright:} \\ C 2015. The Authors. \\ Licensee: AOSIS \\ OpenJournals. This work is \\ licensed under the Creative \\ Commons Attribution \\ License.
}

\section{Read online:}

Orientation: The dire educational situation in South Africa has urged researchers to investigate predictors of sustained student success.

Research purpose: To investigate to what extent an Emotional Intelligence (EI) intervention impacts the level of EI, and critical psychological resources (affect balance, cognitive thoughtpattern strategies as a sub-component of self-leadership, perceived stress and academic selfefficacy) necessary for student success.

Motivation for the study: Non-cognitive personal resources (such as EI) may indirectly contribute to student success.

Research design, approach and method: A controlled experimental research design was conducted to test the effect of an EI developmental intervention on affect balance, academic self-efficacy, cognitive thought-pattern strategies, and perceived stress, using a sample of first-year students $(n=114)$.

Main findings: Limited support of the utility of the intervention to increase EI emerged; whilst stronger support emerged that academic self-efficacy was affected by the intervention. No direct empirical support for the impact of increased EI on the other measured psychological resources was obtained, although some trends in the data could be observed.

Practical/managerial implications: Investments in EI developmental interventions, as part of student-support initiatives, should be further investigated to sufficiently justify its potential to influence sustained student success.

Contribution/value-add: The results of this study lay a foundation that suggest EI could be malleable and influence academic self-efficacy. More research is necessary regarding supplementary teaching and learning initiatives focused on non-cognitive personal resources, which are complementary to the academic offering at tertiary institutions, with the expectation of increasing the student success rates.

\section{Introduction}

The economy of a country is dependent on the degree to which its labour force is educated (Spaull, 2013). Student success in higher education holds the prospect of rewarding employment, but also the enhancement of cultural and social capital, increased health, and better standards of living (Yorke \& Longden, 2005). Unfortunately, institutes for higher education in South Africa have an alarmingly low student success rate. For example, in 2012 Higher Education South Africa (HESA, 2012) reported that of 4791807 individuals between the ages of 20-24, only 18\% had enrolled for higher education programmes. This meagre participation rate is threatened even further as a shocking $45 \%$ of enrolled students do not complete their studies, and $25 \%$ of individuals drop out after their first year of study (Mabelebele, 2012). These statistics highlight a clear threat to South Africa's skilled labour market. Research is needed to better understand predictors of student success at higher education institutions.

Mainstream research has mostly focussed on the predictive validity of cognitive abilities on academic achievement. IQ tests remain a prominent predictor of academic achievement (Grosman \& Johnson, 1982; Neisser et al., 1996). Yet, despite its supremacy, IQ only accounts for roughly $25 \%$ of the variance in academic success (Neisser et al., 1996). Even more surprising is that students with higher cognitive ability do not always excel after school as expected, whilst those with more moderate intellectual abilities sometimes achieve greater success (Stein \& Book, 2011). This suggests that other factors may play an important role in determining student success. 


\section{The role of El in student success}

It is argued in this study that a student's emotional intelligence could play a significant role in student success, as it could influence other personal resources (Lyubomirsky, King \& Diener, 2005; Mayer \& Salovey, 1997), such as:

- $\quad$ self-efficacy (Hen \& Goroshit, 2012

- the ability to regulate affective states

- $\quad$ stress (Görgens-Ekermans \& Brand, 2012)

- self-leadership (Manz, 1992).

These are all deemed to be important in increasing the chances of attaining academic success. Emotional intelligence (EI) refers to the capacity to deal effectively with one's own and others' emotions. When applied to the academic environment, 'EI involves the capacity to effectively perceive, express, understand, and manage emotions in a professional and effective manner at work' (Palmer \& Stough, 2001, p. 1), which is, when studying.

In this study EI is, therefore, viewed as a key personal resource that could facilitate the acquisition and maintenance of other psychological resources that may contribute to student success. A growing body of evidence suggests that exposure to an EI developmental intervention may improve EI (e.g. Nelis, Quoidbach, Mikolajczak \& Hansenne, 2009; Fletcher et al., 2009; Wood, Wood, Zohar, Bates \& Parker, 2006). The purpose of this study was, therefore, to investigate whether or not it is possible to elevate levels of EI and influence various psychological resources (e.g. affect balance, ASL, ASE, and perceived stress) in students, by exposing them to a developmental EI training intervention.

\section{Theoretical approaches governing this study}

Students mostly withdraw from university for reasons unrelated to their cognitive ability (Pancer, Hunsberger, Pratt \& Alisat, 2000). Unique challenges (see Parker, Summerfeldt, Hogan \& Majeski, 2004) and stressors (e.g. frequent evaluations, time pressures; Chambel \& Curral, 2005) require higher levels of independence, initiative, and effective selfregulation (Bryde \& Milburn, 1990; Zimmerman, 1989), and also a positive disposition and self-confidence (Chemers, $\mathrm{Hu} \&$ Garcia, 2001), to maximise the chances of academic success. This study asserts that an individual's EI could play a significant role in overcoming these challenges.

One of the key outcomes of EI is the ability to maintain a positive affective state and deal effectively with negative emotions. It is, therefore, argued that individuals with higher EI experience more frequent positive emotions than negative emotions (i.e. a healthier affect balance). Moreover, it is argued that increased EI, and increased experiences of positive emotions, could influence student success as it may impact on the acquisition and maintenance of various other psychological resources (e.g. improved self-efficacy and less stress). In order to explicate the dynamics of how higher EI may lead to the increased acquisition and maintenance of other personal resources (e.g. self-efficacy), two theoretical approaches - nestled within the positive psychology paradigm (Seligman \& Csikszentmihalyi, 2000) - are drawn upon. These are the Broaden and Build Theory of Positive Emotions (Fredrickson, 2004), and the Conservation of Resources Theory (Hobfoll, 1989).

Fredrickson (2004) hypothesised that positive emotions broaden an individual's momentary thought-action repertoire - enabling an individual to build a variety of sustainable personal resources. These personal resources include physical resources (e.g. physical skills or health), social resources (e.g. friendships and socialsupport networks), intellectual resources (e.g. knowledge, intellectual complexity, executive control, theory of mind) and psychological resources (e.g. resilience, optimism, creativity). The Conservation of Resources (COR) theory (Hobfoll, 1989) stipulates that individuals strive to obtain, retain, protect and foster resources (i.e. any object, personal characteristic, condition or energy), and that individuals with more resources are less vulnerable to resource loss than others, and are more capable of organising resource gain (Hobfoll, 2001).

The afore-mentioned two theories hold important implications for this study. Based on Fredrickson's (2004) research it is argued that students with higher EI may experience more frequent positive emotions and should be inclined to more easily obtain other psychological resources (for example, ASE and ASL), thus, increasing the chances of academic success. It is furthermore argued that such increased access to psychological resources used to cope with typical student stressors, as a result of higher EI, could result in a resource-gain spiral (according to COR theory), which should further impact on academic success.

\section{The link between El and psychological resources necessary for sustained student success}

Four central tenets of this study aim to explicate why EI could be crucial to sustained academic student success. Firstly, essential to EI is emotional regulation, which embodies the ability to maintain a positive affective state and deal effectively with negative emotions (the emotional management and control dimensions of EI). Empirical evidence seems to support the link between positive affect and success. Various studies have demonstrated that positive affect leads to:

- healthy social interactions and support from others (Staw, Sutton \& Pelled, 1994)

- a sense of mastery (Luebbers, Downey \& Stough, 2007)

- better self-esteem (Lucas, Diener \& Suh, 1996)

- psychological well-being (Fredrickson \& Joiner, 2002)

- the ability to cope with stress (Carver et al., 1993)

- satisfaction with ones' studies and life in general (Ojeda, Flores \& Navarro, 2011).

Positive affect in this study implies the maintenance of an optimistic disposition and not merely the experience of positive emotions per se. It is argued that a healthy affect 
balance should be more easily attainable for those individuals with higher EI. Frequently experienced positive emotions and relatively few negative emotions, facilitate a favourable affect balance and could, according to Fredrickson's theory (2004), boost the acquisition and maintenance of various other personal resources.

Secondly, higher EI has been associated with more selfefficacy beliefs (Hen \& Goroshit, 2012) which are critical for academic performance and adaption (Bandura, 1997). Selfefficacy is defined as an individual's judgment about their own intrinsic ability to organise and execute courses of action to attain certain performance outcomes with which they are satisfied (Bandura, 1997). It is well known that affective states are an important source of self-efficacy beliefs (Bandura, 1997). It is argued that EI could help promote a healthy affect balance (i.e. more frequently experienced positive affect) and should, therefore, contribute to higher levels of self-efficacy beliefs (Hashemi \& Ghanizadeh, 2011). Multon, Brown and Lent (1991) report that self-efficacy explains approximately $14 \%$ of variance in the academic achievement of students. Individuals who believe in their capabilities will put in more effort (Prat-Sala \& Redford, 2010) and persist longer with their studies (Lent, Brown \& Larkin, 1984), than those with lower levels of academic self-efficacy. Furthermore, self-efficacy beliefs influence the way in which events are interpreted. Individuals with a weak self-efficacy view challenges as a threat which might cause them to experience psychological distress. Various studies have reported positive relationships between student self-efficacy and academic achievement (Brady-Amoon \& Fuertes, 2011; Chemers et al., 2001). Furthermore self-efficacy has been shown to assist in student adjustment (Brady-Amoon \& Fuertes, 2011) and coping with negative emotional states such as test anxiety and low levels of motivation (Bandura, 1993).

Thirdly, EI buffers against the negative effects of stress (Görgens-Ekermans \& Brand, 2012) and enhances an individual's overall sense of well-being, allowing for optimal human performance and success (Fredrickson \& Losada, 2005). Findings indicate that higher levels of stress result in less engagement with study material (Entwistle \& Tait, 1990), less time spent actually studying (Chow, 2007), lower levels of exam success (Goldsmith \& Albretech, 1993), and fewer completed courses (Chambel \& Curral, 2005). Individuals with higher EI, process information of an emotional nature more easily, and effectively integrate their emotions with thoughts and behaviours, so enabling them to become resilient to stressful situations (Mayer, Salovey \& Caruso, 2000).

Fourthly, it is posited that increased EI may positively influence student self-leadership behaviours. Self-leadership is defined as the process through which individuals influence themselves (behavioural and cognitive strategies) to establish the essential self-direction and self-motivation needed for effective performance (Houghton \& Neck, 2002; Manz, 1992; Neck \& Houghton, 2006; Neck \& Manz, 2010). It is argued in this study that the Cognitive Thought Pattern Strategies
(CTPS) component of self-leadership could be influenced by increased EI. CTPS involves the, 'creation and maintenance of functional patterns of habitual thinking' (Houghton \& Neck, 2002, p. 674). Specific strategies incorporated in CTPS include positive self-talk, the appraisal and rethinking of irrational beliefs and assumptions, and creating mental imagery of successful future performance. Depape, HakimLarson, Voelker, Page and Jackson (2006), for example, showed that self-talk (a cognitive thought-pattern strategy) and EI are positively related. EI focuses on the ability to regulate emotions, whilst self-leadership is concerned with the regulation of thought processes and behaviour (Boss \& Sims, 2008; D'Intino, Goldsby, Houghton \& Neck, 2007). According to Boss and Sims (2008), these two constructs may be '... two peas in the same self-regulatory pot' (p. 142). Emotions can have a powerful impact on both our cognitive processes and behaviour. It is, therefore, argued that individuals with higher EI will probably be better at utilising CTPS to facilitate self-leadership, in order to attain academic success.

Given the above-mentioned arguments, it is suggested that EI could play a pivotal role in some of the psychological processes that underlie student success, as it may be instrumental in the enhancement of a healthy affect balance, academic self-efficacy, academic self-leadership, and the reduction of stress. EI is, therefore, viewed as a key personal resource that could facilitate the acquisition and maintenance of other psychological resources that contribute to student success. There is a growing body of research that supports the link between EI and academic success (Keefer, Parker \& Wood, 2012; Parker, Hogan, Eastabrook, Oke \& Wood, 2006). However, this study attempts to explicate some of the psychological processes that may underlie this link.

\section{The development of El}

Various studies have shown favourable results in terms of developing EI both at school (e.g. Eastabrook, Duncan \& Eldridge, 2005) and tertiary education level (e.g. Chang, 2007; Fletcher et al., 2009). Similar results were found in a series of South African studies, all of which followed similar controlled experimental designs and used adapted versions of the Gardner (2005) EI development programme (based on the Swinburne University Emotional Intelligence Test [SUEIT] EI model). The experimental design and choice of development program was replicated in this study. Burger (2009) investigated the effects of EI development on teacher well-being. Positive relationships were found between EI and well-being, and the experimental group showed increases in EI levels resulting from the training intervention. ${ }^{1} \mathrm{~A}$ followup study was conducted by Görgens-Ekermans and Swart (2011) which investigated the effects of EI development on stress management. The sample (both control and experimental groups) consisted of 50 postgraduate students

1.It should be noted that although these trends were clearly evident in the data, the results were not statistically significant resulting from the small sample size. Furthermore, this study had several limitations, of which the absence of a control group was the most important. 
and revealed a significant increase in EI scores for the group who received the training. Furthermore, a six-month followup showed further significant increases in the experimental group EI scores (with none for the control group), supporting the longevity of the effects of this EI development programme. Also reported was a significant drop in selfreported stress (Perceived Stress Scale: Cohen, Kamarck \& Mermelstein, 1983) before and after the intervention, with a further downward trend at the six-month followup. All these results were statistically significant. Herman (2012) investigated the effects of EI development on work engagement within a corporate company, using a sample of management and non-management employees. There were increases in the experimental group's EI levels, with no such trend in the control group; however, the results were non-significant. The results of all of these studies seem to suggest that EI is a somewhat malleable construct that can be developed through training programmes and interventions. Vandervoort (2006) believes that these EI training programmes should form part of the curricula of universities, as they hold various personal, social and societal benefits.

\section{Research objectives and hypotheses}

This study is unique as it is the first notable South African study - to the knowledge of the researchers - to investigate the usage of an EI training programme, with the aim of enhancing the personal psychological resources of students, which could ultimately affect their academic success. The research question for this study was, 'Is it possible to increase $\mathrm{EI}$ and influence various psychological resources (e.g. affect balance, ASL, ASE, and perceived stress) in students, by exposing them to a developmental EI training intervention?' The following hypotheses were tested:

Hypothesis 1: Emotional Intelligence-Total scores on Emotional Intelligence will increase significantly following participation in the EI development intervention.

Hypothesis 2: Affect Balance - Affect Balance scores will increase significantly following participation in the EI development intervention.

Hypothesis 3: Academic Self-efficacy - Academic Self-Efficacy scores will increase significantly following participation in the EI development intervention.

Hypothesis 4: Cognitive Thought Pattern Strategies - CTPS scores will increase significantly following participation in the EI development intervention.

Hypothesis 5: Stress - Perceived stress scores will decrease significantly following participation in the EI development intervention.

If the necessary empirical evidence can be provided for the utility of an EI development programme in a university context, it could be the first step towards sensitising academic institutions, with respect to the need for the development of EI as a basic, non-cognitive capacity to help facilitate academic and life success in first-year students.

\section{Research design Research approach}

A controlled experimental research design - that is, a twogroup non-equivalent design - was used, implying that the participants were not randomly assigned to the groups and only the experimental group was exposed to the EI training intervention (Goldstein, 1993). This design is often used in educational settings where there are 'naturally assembled groups, such as classes' (Goldstein, 1993, pp. 202-203), as was the case in this study, and is the preferred design if there is no other available alternative. The more similar the groups are in the pre-test, the higher the level of control for some internal validity threats, such as pretesting and history as it would have affected both groups equally (Goldstein, 1993; Goldstein \& Ford, 2001).

According to Ghiselli, Campbell and Zedek (1981, p. 249) it is, 'desirable to maximize the interval between testing occasions to minimize the effects of memory'. Therefore, all participants were measured on all the variables (EI, affect balance, cognitive thought-pattern strategies, academic self-efficacy, and perceived stress) one week prior to the intervention (T1), immediately after the intervention was completed (T2, 6 weeks later), and three months thereafter (T3) to assess the sustainability of changes in the scores. According to Goldstein (1993, p. 189) the necessary time period between the intervention and post-test is difficult to estimate, but he states that participants should have been in the transfer situation for a '... reasonable time' period before the post-test is administered. The three month follow-up testing was, therefore, conducted to assess the sustainability of changes in the scores.

The questionnaire package consisted of the Swinburne University Emotional Intelligence Test (Palmer \& Stough, 2001), the Perceived Stress Scale (Cohen et al., 1983), the Academic Self-Efficacy scale (Burger, 2011), the CTPS sub-scale of the Academic Self-Leadership Questionnaire (Houghton \& Neck, 2002), and the Scale of Positive and Negative Experience (Diener et al., 2009).

\section{Research method Research participants}

First-year extended degree programme students (44.7\% male; $55.3 \%$ female; age: mean $=18.63, \mathrm{SD}=1.45$; ethnic composition: $33.3 \%$ white; $43 \%$ mixed-race; $21.1 \%$ black African; $2.7 \%$ other or missing) from two different faculties (Economic and Management Sciences [EMS]; Natural Sciences, [NS]) at the participating tertiary education institution were invited to participate, and decide on the nature of their participation (i.e. in either the experimental or control group based on individual availability). The aim was to secure a more or less equal number of students from both faculties, in both groups. An initial sample of 114 participants was recruited (EMS experimental group: $n=46$, control group: $n=22$; NS experimental group: $n=21$, control group: $n=25$ ). The fallout 
rate (i.e. participants who did not complete the training or who were absent from testing) throughout the research was relatively high (33.3\%). However, given that the mixedmodel $^{2}$ repeated measures ANOVA data-analysis technique was used, all cases available at each assessment stage were included in the analyses. Participation in the study was completely voluntary and the student's consent was obtained before-hand.

\section{Research procedure}

The objective of the EI training programme was to create awareness about emotions, to facilitate better understanding of emotions, and to teach students how to effectively manage and control their emotional states. The structure and content of the training programme originated from the work of Gardner (2005), and is based on the SUEIT's (Palmer \& Stough, 2001) conceptual framework and dimensions of EI. Through a series of South African studies (Ekermans, Burger, Swart, Saklofske \& Poole, 2010; Görgens-Ekermans \& Swart, 2011; Herman, 2012) the programme has been adapted and refined for the local context. The small group training sessions (four students and one facilitator) consisted of 2-hour weekly contact sessions, which were delivered over a period of five consecutive weeks.

EI should be developed in stages, from basic psychological processes (such as Emotional Recognition and Expression) to more complex psychologically integrated processes (such as Emotional Management and Emotional Control) (Mayer \& Salovey, 1997). The training programme followed this structure. Each participant received a workbook. Learning goals were formulated for each of the sessions, based on the target variables of that session. Participants were encouraged to share their own emotional experiences and to comment on the experiences of others. A variety of techniques were utilised, including group interaction, feedback, and individual training tasks. Participants were given exercises after each session for completion during the week. The next session would start with feedback and reflection on the exercises.

\section{Measuring instruments}

Emotional Intelligence: Emotional Intelligence was assessed by the Swinburne University Emotional Intelligence Test (SUEIT) (Palmer \& Stough, 2001). The SUEIT is a self-report measure, designed to assess the way in which individuals typically think, feel and act with emotions. The instrument provides an overall EI score, and also scores on each of the five subscales of the model. These include:

1. Emotional Recognition and Expression - the ability to identify one's own feelings and emotional states, and the ability to accurately express those feelings to others

2. Understanding Emotions - the ability to identify and understand the emotions of others and those manifested in external stimuli

2.The mixed-model repeated measures ANOVA differs from multivariate repeated measures ANOVA, as an incomplete dataset can be used for the analyses. For the
latter, only the 76 complete cases could have been included. However, with the latter, only the 76 complete cases could have
former, all the available data could be utilised.
3. Emotions Direct Cognition ${ }^{3}$ - the extent to which emotional knowledge is incorporated in decision making, and/or problem solving

4. Emotional Management - the ability to manage positive and negative emotions both within oneself and others

5. Emotional Control - the ability to effectively control strong emotional states, such as anger, stress, anxiety and frustration (Palmer \& Stough, 2001, p. 1).

The SUEIT consists of 64 items, and is scored on a five-point Likert scale. Previous South African studies (e.g. GörgensEkermans \& Brand, 2012; Herman, 2012) have reported Cronbach Alphas for the SUEIT total score ranging between $\alpha=0.83$ to 0.89 , whilst Görgens-Ekermans and Swart (2011) reported reliability coefficients over three testing periods ranging from $\alpha=0.65$ to 0.72 . In the current study, good internal stability coefficients for the three testing sessions emerged (Nunnally \& Bernstein, 1994), with Cronbach alphas ranging from 0.88 to 0.94 for the EI total score. In addition, the stability coefficient from the T1 to T2 testing was $r=0.48$, and three months thereafter (at the T3 testing) $r=0.82$.

Affect balance: The affective states of students were measured by the 12 item Scale of Positive and Negative Experiences (SPANE) with six Likert type items devoted to positive and negative experiences respectively (Diener et al., 2009, 2010). The SPANE includes rather broad descriptions for positive and negative feelings, and also a number of positive and negative emotions that are fundamental to the experience of well-being. Each item is scored on a five-point Likert-type scale, ranging from very rarely (1) to very often or always (5). The positive scale (SPANE-P) and negative scale (SPANE-N) is scored separately, but can be combined into a summary scale (SPANE-B) by subtracting the negative score from the positive score. SPANE-B scores, therefore, range from -24 to 24 and reflect a measure of affect balance (i.e. a measure of an individual's overall affective state). Anegative affect balanceimplies that a participant experiences more negative emotional states, as compared to positive ones. A higher score is, therefore, desired. Previous studies (Diener et al., 2009, 2010) have reported good internal consistency for the three subscales, with alphas ranging from 0.84 to 0.92 for SPANE-P, 0.80 to 0.91 for SPANE-N, and 0.88 to 0.92 for SPANE-B. In the current study, good internal-stability coefficients emerged (Nunnally \& Bernstein, 1994), with Cronbach Alphas ranging from 0.78 to 0.87 for SPANE-P, 0.83 to 0.87 for SPANE-N and 0.85 to 0.91 for SPANE-B over the three testing periods. The stability coefficient for the SPANE-B was $r=0.61$ after six weeks, and $r=0.71$ after 3 months.

Academic self-efficacy: This refers to an individual's belief regarding their capacity to learn and perform academic tasks effectively. The Academic Self-efficacy (ASE) scale

\footnotetext{
3.The 'emotions direct cognition' sub-dimension of the SUEIT was not included in the con This dimention rerention, and was also not the calculation of the total El score. This dimension refor in decision making. It has a strong link to preferred decision-making styles, and these are not deemed to be as malleable as the other El sub-dimensions in the SUEIT model.
} 
constructed by Burger (2011) was used in this study. The scale consists of 12 items scored on a seven-point Likert scale, ranging from never (0) to always (6). Burger (2011) reported a Cronbach's Alpha of .906 for the scale. The results of this study indicated satisfactory internal stability (Nunnally \& Bernstein, 1994), as the Cronbach alphas over the three testing periods for the scale ranged from 0.91 to 0.93 . In addition, the stability coefficient from the T1 to T2 testing was $r=0.58$, and three months thereafter (at the T3 testing) $r=0.75$.

Self-leadership: Self-leadership was measured with the Revised Self-Leadership Questionnaire (RSLQ) (Houghton \& Neck, 2002). The RSLQ has 35 items that load onto 9 firstorder factors (self-goal setting; self-reward; self-punishment; self-observation; self-cueing; natural rewards; visualising successful performance; self-talk; and evaluating beliefs and assumptions). The scale utilises a five-point Likert response scale, ranging from not at all accurate (1) to completely accurate (5). Three second-order factors of self-leadership behaviours manifested in the three core strategies, these are: behavioural focus strategies, natural reward-focussed strategies, and cognitive thought-pattern strategies (CTPS), further underlie the instrument (Norris, 2008). Cronbach Alphas coefficients for the 9 first-order factors range from 0.74 to 0.93 (Houghton \& Neck, 2002), with similar results (alphas ranging from 0.78 to 0.88 ) having been reported for the second-order factors (Norris, 2008). Only the cognitive thought-pattern strategies factor (CTPS) (consisting of the visualising success, self-talk, and evaluating beliefs and assumptions subscales from the RSLQ) was utilised in this research. Satisfactory (Nunnally \& Bernstein, 1994) internal stability coefficients over the three testing periods for the CTPS total score and subscales were obtained. The Cronbach alphas ranged from 0.82 to 0.89 for the total score, and from 0.70 to 0.90 for the subscales. The stability coefficient for the CTPS total score was $r=0.68$ after six weeks, and $r=0.69$ after 3 months.

Stress: Perceived stress was measured with the Perceived Stress Scale (14-item version) developed by Cohen et al., (1983). The items were designed to tap into the degree to which respondents experience their lives as unpredictable, uncontrollable and overloading, and are scored on a fivepoint Likert scale ranging from never (0) to very often (4). The instrument has been shown to have good internal consistency. Cronbach Alpha values for 3 samples reported in the validation study were $0.84,0.85$ and 0.86 (Cohen et al.,
1983). Results from South African studies have revealed similar results (e.g. $\alpha=0.83$, Görgens-Ekermans \& Herbert, 2013; alphas ranging from 0.79 to 0.84 , Görgens-Ekermans \& Swart, 2011). Satisfactory (Nunnally \& Bernstein, 1994) internal consistency was evident in this study, with the Cronbach alpha values ranging from 0.82 to 0.87 (for the perceived stress total score) over the three testing times. In addition, the stability coefficient for the stress total score was $r=0.31$ after six weeks, and $r=0.67$ after 3 months.

\section{Statistical analysis}

The data were analysed with STATISTICA (Statsoft Inc., 2012). Internal consistency (Cronbach's alpha) and testretest reliability (i.e. stability coefficients) (results discussed in the 'measuring instruments' section) were determined for all the measurement instruments, and descriptive statistics (Table 1) were calculated for all the study variables. A series of between-group comparisons, by means of a mixed model repeated measures of ANOVA (West, Welch, Galecki \& Gillespie, 2007) were performed to investigate the differences between levels of EI, CTPS, affect balance, ASE, and stress at the pre-test (T1), post-test 1 (T2) and post-test 2 (T3) testing. In addition, post-hoc comparisons were calculated (i.e. the Least Significance Difference test; LSD test), in order to test the difference between, and amongst, particular group means.

\section{Results}

A significant time-by-group interaction effect would indicate that there were significant differences between the experimental and control groups over the three testing times. The significance of the time-by-group interaction for all the variables is shown in Table 1 .

The EI results revealed that the total effect for group-by-time was significant (see Table 1). Post-hoc comparisons (Table 2) revealed that the experimental group showed significant increases for EI levels from the pre-test to the first post-test, but no significant increase from the first to second post-test. The latter finding may have been affected by the time-frame of the second follow-up assessment. The continued development and internalisation of EI skills may take slightly longer to surface, as evidenced in the six-month follow up assessments in the Nelis et al. (2009) and Görgens-Ekermans and Swart (2011) studies. Contrary to what was expected, the control

TABLE 1: Descriptive statistics and mixed-model Repeated-measures ANOVA results.

\begin{tabular}{|c|c|c|c|c|c|c|c|c|c|c|c|c|c|c|}
\hline \multirow[t]{3}{*}{ Variable } & \multicolumn{4}{|c|}{ Pre-test } & \multicolumn{4}{|c|}{ Post-test 1} & \multicolumn{4}{|c|}{ Post-test 2} & \multirow[t]{3}{*}{ Time $x$ group $(p)$} & \multirow[t]{3}{*}{$F$} \\
\hline & \multicolumn{2}{|c|}{$M$} & \multicolumn{2}{|c|}{ SD } & \multicolumn{2}{|c|}{$M$} & \multicolumn{2}{|c|}{ SD } & \multicolumn{2}{|c|}{$\mathrm{M}$} & \multicolumn{2}{|c|}{ SD } & & \\
\hline & Exp & Cont & Exp & Cont & Exp & Cont & Exp & Cont & Exp & Cont & Exp & Cont & & \\
\hline EI & 170.63 & 170.14 & 17.56 & 20.34 & 188.93 & 178.69 & 20.27 & 24.55 & 187.66 & 179.20 & 23.74 & 22.79 & $0.014^{*}$ & 4.358 \\
\hline$A B$ & 7.25 & 7.44 & 7.42 & 6.74 & 10.65 & 8.74 & 7.17 & 8.37 & 8.68 & 9.40 & 7.53 & 6.84 & 0.131 & 2.056 \\
\hline CTPS & 43.98 & 46.09 & 8.23 & 7.04 & 45.93 & 46.37 & 8.42 & 7.31 & 45.85 & 47.31 & 8.61 & 7.31 & 0.280 & 1.282 \\
\hline ASE & 49.44 & 52.19 & 9.96 & 8.72 & 53.93 & 53.03 & 8.94 & 8.12 & 52.71 & 52.63 & 10.21 & 8.64 & $0.020 *$ & 3.975 \\
\hline PS & 40.35 & 40.42 & 7.55 & 7.39 & 34.61 & 37.52 & 6.48 & 8.27 & 36.59 & 37.71 & 8.14 & 6.69 & 0.162 & 1.839 \\
\hline
\end{tabular}

M, mean; SD, standard deviation; Exp, experimental group; Cont, control group; El, Emotional Intelligence; AB, Affect Balance; CTPS, Cognitive Thought Pattern Strategies; ASE, Academic Self$\mathrm{M}$, mean; SD, standard deviation; Exp, expe
Efficacy; PS, Perceived Stress; F, F-ration. $*, p \leq 0.05$ 
TABLE 2: Least Significance Difference test (post-hoc) results for total El (Effect: Group*time).

\begin{tabular}{|c|c|c|c|c|c|c|c|}
\hline Treatment & Time & Control (T1) & Control (T2) & Control (T3) & Experimental ( T1) & Experimental (T2) & Experimental (T3) \\
\hline Control & T1 & - & - & - & - & - & - \\
\hline Control & $\mathrm{T} 2$ & $0.003 *$ & - & - & - & - & - \\
\hline Control & T3 & $0.014 *$ & 0.965 & - & - & - & - \\
\hline Experimental & $\mathrm{T} 1$ & 0.904 & 0.082 & 0.112 & - & - & - \\
\hline Experimental & $\mathrm{T} 2$ & $0.000 *$ & $0.007^{*}$ & $0.011^{*}$ & $0.000 *$ & - & - \\
\hline Experimental & T3 & $0.000 *$ & $0.028 *$ & $0.037 *$ & $0.000 *$ & 0.522 & - \\
\hline
\end{tabular}

T1, Time one testing; T2, Time two testing; $\mathrm{T} 3$, Time three testing. $*, p \leq 0.05$

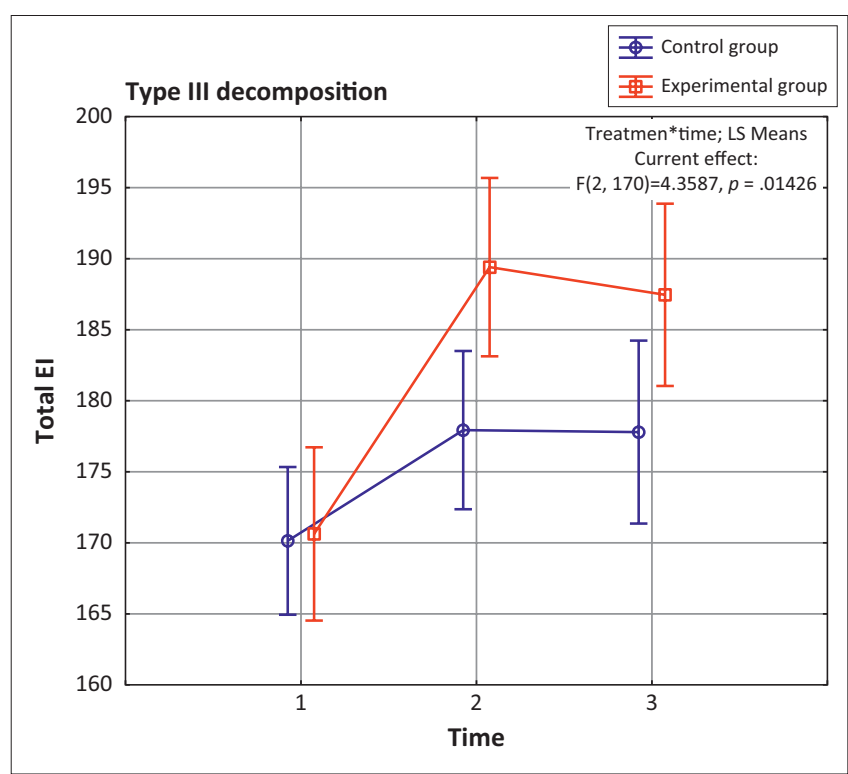

Vertical bars denote 0.95 confidence intervals.

FIGURE 1: Time-by-group interaction: Emotional intelligence.

group also showed significant increases from the pre-test to first post-test testing, which could possibly be attributed to maturation or test, retest effects (Babbie \& Mouton, 2010; Campbell \& Stanley, 1963). However, the increase in the experimental group score was notably greater in magnitude than that of the control group (see Figure 1). It is argued that the EI training programme implemented in the current study may have been responsible for these differences in magnitude of change between the control and experimental groups, if equal maturation effects or effects of testing and retesting are assumed for both groups. Partial weak empirical support for Hypothesis 1 was, therefore, obtained. These findings provide some further support for the notion that emotional responses and behaviours can be learned and developed in individuals (Chang, 2007; Fletcher et al., 2009; GörgensEkermans \& Swart, 2011; Nelis et al., 2009; Wood et al., 2006).

The results revealed (Table 1) that the total effect for the group-by-time interaction for ASE was significant. Very minor fluctuations (non-significant, Table 3) in controlgroup mean scores were observed (Table 1) over the three assessments. In contrast, a significant increase from the pre-test to first post-test assessment was evident for the experimental group, whilst a very slight decrease (non-significant) was observed at the second post-test (Table 1 and Table 3). Contrary to the close similarity in EI levels for both groups at the pre-test assessment, the results revealed that the experimental group started out with notably lower levels of ASE (see Table 1, Figure 2) compared to the control-group students (non-significant difference, Table 3). This may be the result of a self-selection or selection bias effect (Babbie \& Mouton, 2010; Campbell \& Stanley, 1963), where individuals who allocated themselves to the treatment group doubted their academic abilities and hence sought assistance in this regard. In contrast, the control-group participants most likely felt confident in their academic pursuits and opted not to participate in the EI programme. Relatively strong support for Hypothesis 3 was obtained.

The total effect for the group-by-time interaction for affect balance, CTPS, and stress was non-significant (Table 1). No support for Hypotheses 2, 4 and 5 were obtained. However, some trends were observed in the data, which could suggest that the intervention may have had a limited effect on these variables. For example, a significant mean score increase for the experimental group in CTPS was evident from the pre to first post-test assessment $(p=0.044)$, with similar levels evident from the post-test 1 to 2 assessments (Table 1). As expected, very minor fluctuations (non-significant) in controlgroup mean scores were observed (Table 1) over the three assessments (Figure 3). A self-selection or selection bias effect (Babbie \& Mouton, 2010; Campbell \& Stanley, 1963) may account for the differences in CTPS pre-test scores between the groups (non-significant). It could be argued that controlgroup participants opted not to participate in the intervention, as they perceived their self-leadership thought, and behaviour processes regarding, the learning activities, and their overall academic performance, to be adequate, at least.

A fairly similar trend was evident in the affect balance data. Once again, the mean score increase from the pre to first posttest assessment for the experimental group was significant ( $p=0.001)$, but, unfortunately, these changes were not sustained at the post-test 2 assessment. This may be the result of the state-like nature of affect balance (Diener \& Seligman, 2002), which is more easily affected by external factors (e.g. the post-test 2 assessment occurred shortly before the June examinations). Notwithstanding this limitation, it is interesting to note that, once again, almost no fluctuation in the affect balance scores for the control group was observed over the three assessments (Table 1, Figure 4). Baseline pretest scores were relatively similar for the two groups.

A fairly similar trend in partial support (albeit nonsignificant) for the utility of the EI intervention was evident from the stress results. Although both groups showed 
TABLE 3: Least Significance Difference test (post-hoc) results for ASE (Effect: Group*time).

\begin{tabular}{|c|c|c|c|c|c|c|c|}
\hline Treatment & Time & Control ( T1) & Control (T2) & Control (T3) & Experimental (T1) & Experimental (T2) & Experimental (T3) \\
\hline Control & $\mathrm{T} 1$ & - & - & - & - & - & - \\
\hline Control & $\mathrm{T} 2$ & 0.542 & - & - & - & - & - \\
\hline Control & T3 & 0.926 & 0.675 & - & - & - & - \\
\hline Experimental & $\mathrm{T} 1$ & 0.109 & 0.054 & 0.129 & - & - & - \\
\hline Experimental & $\mathrm{T} 2$ & 0.225 & 0.415 & 0.297 & $0.000 *$ & - & - \\
\hline Experimental & T3 & 0.535 & 0.808 & 0.613 & $0.002 *$ & 0.412 & - \\
\hline
\end{tabular}

T1, Time one testing; $\mathrm{T} 2$, Time two testing; T3, Time three testing. $*, p \leq 0.05$

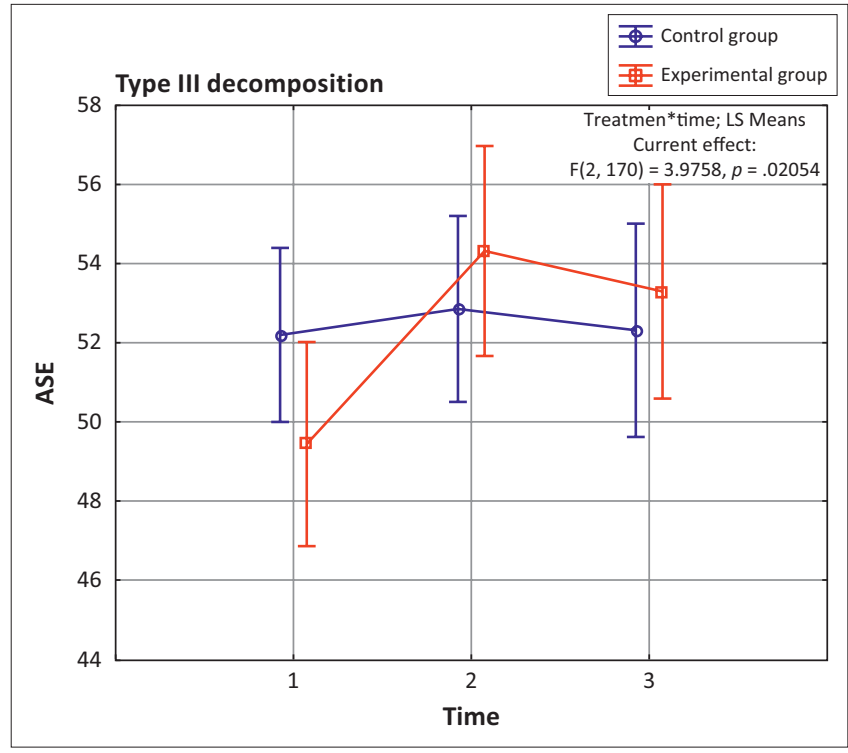

Vertical bars denote 0.95 confidence intervals.

FIGURE 2: Time-by-group interaction: Academic self-efficacy.

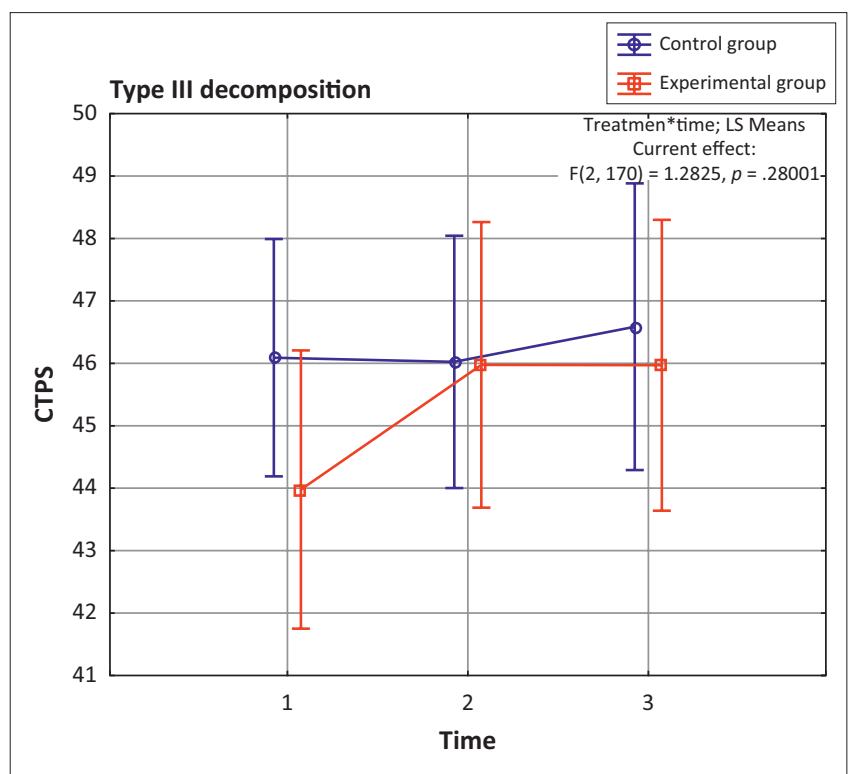

Vertical bars denote 0.95 confidence intervals.

FIGURE 3: Time-by-group interaction: Cognitive thought-pattern strategies.

significant decreases in perceived stress at the post-test 1 assessment (Table 1, $\mathrm{p}_{\text {experimental }}=0.000 ; \mathrm{p}_{\text {control }}=0.007$ ), it should be noted that the magnitude of change in levels for the experimental group was notably larger than that of the control group. Scores for both the groups increased slightly (non-significant) from the first to second post-test assessment

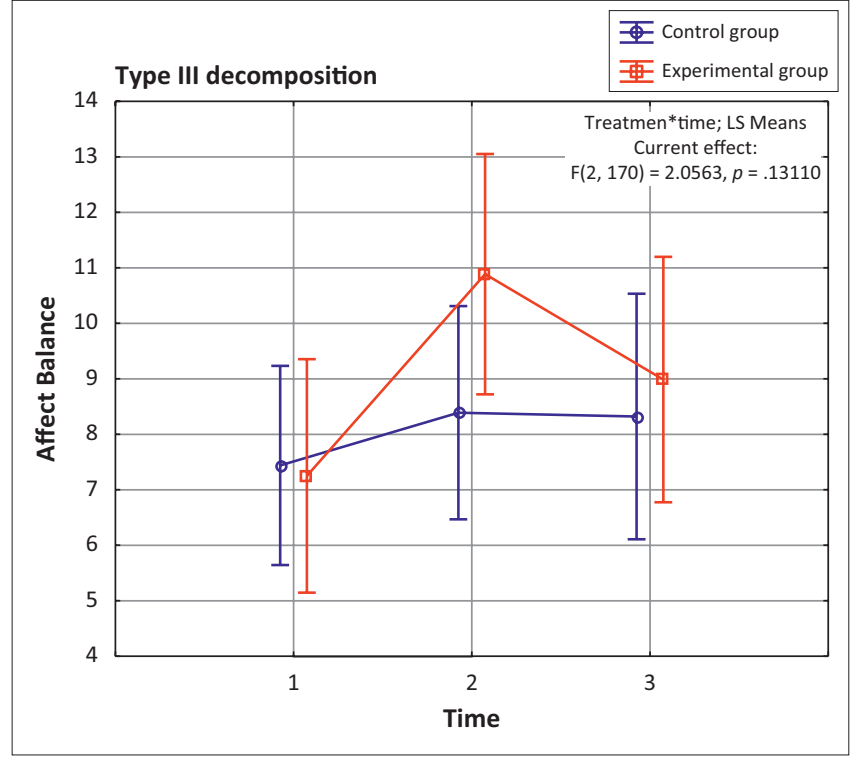

Vertical bars denote 0.95 confidence intervals.

FIGURE 4: Time-by-group interaction: Affect balance.

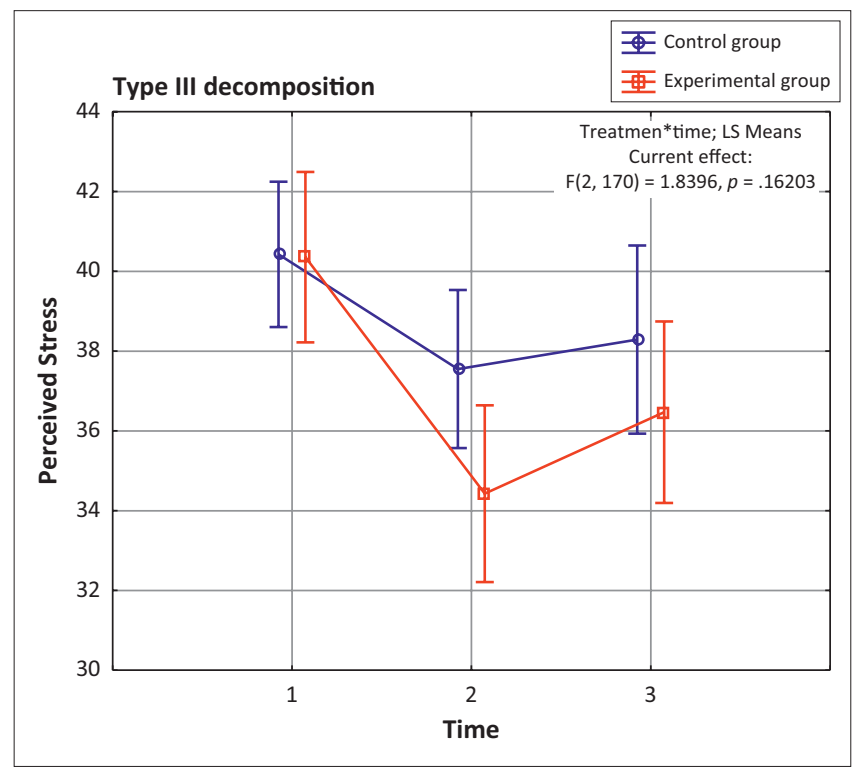

Vertical bars denote 0.95 confidence intervals.

FIGURE 5: Time-by-group interaction: Perceived stress.

(Table 1). It could be argued that some validity threats (e.g. history, Babbie \& Mouton, 2010) may account for these fluctuating results. For example, it is possible that the timing of the first post-test assessment (close to the mid-semester break) and second post-test assessment (close to the start of the mid-year examinations) may have influenced perceived 
stress levels. However, it should be noted that given that both groups obtained relatively similar baseline pre-test scores (Table 1), the change to the second post assessment for the experimental group was significant $(p=0.001)$, whereas this change for the control group was non-significant ( $p=0.088)$. This could be interpreted to suggest that - despite the observed fluctuations possibly resulting from external events affecting all students in both groups - the developmental intervention may have had a slight, positive, impact on the perceived stress levels of the experimental group students.

\section{Discussion}

The challenging educational situation in South Africa highlights the need to build on factors relating to student success, in order to not only elevate the number of new entries in tertiary educational institutes, but also to maintain and complete such entries. The predictive validity of cognitive ability in academic success is limited (e.g. Neisser et al., 1996), most probably because of the non-academic or social nature of most challenges faced by many students (Bryde \& Milburn, 1990). The idea that EI could be beneficial for students has gained momentum in the academic community (e.g. Parker et al., 2004, Sparkman, Maulding, \& Roberts 2012).

The positive psychology paradigm (Seligman \& Csikszentmihalyi, 2000) has brought valuable insights into the enhancement of individual performance and success, by increasing our understanding of how to empower individuals with the necessary skills and capabilities to allow for success and growth. It is argued that, central to this theme of optimal student functioning, is a student's affective state, which has been shown to have a significant impact on their success (Abe, 2011; Lyubomirsky et al., 2005). This phenomenon could be explained by The Broaden and Build Theory of Positive Emotions (Fredrickson, 2004), which stipulates that positive emotions broaden an individual's momentary thoughtaction repertoire, so allowing them to pursue a wider range of thoughts and actions than they typically would. In addition, according to Conservation of Resources Theory (Hobfoll, 1989), individuals who have personal resources like frequent positive affect or EI, can more easily acquire additional resources. Therefore, it was argued that by developing the EI of students, an outcome of more frequently experienced positive affect (as resembled in higher affect balance scores) could be expected. Moreover, a positive gain spiral could result according to COR theory (Hobfoll, 1989), so helping with the acquisition and maintenance of various other personal resources (such as ASL, self-efficacy, and less perceived stress), which could be critical for academic success. The above considered, the current study implemented and evaluated an EI development intervention for first-year students at a South African university.

It was, firstly, hypothesised that EI levels would increase significantly following participation in the EI developmental intervention. The results revealed a significant increase in total EI scores (pre-test to first post-test), for those individuals who participated in the intervention. However, a similar trend of a smaller magnitude was found in the control group, highlighting the possible effects of some validity threats on the data (e.g. test-retesting, compensatory rivalry, Babbie \& Mouton, 2010; Goldstein, 1993). For example, maturation effects (Babbie \& Mouton, 2010) may account for a portion of these changes, as Parker, Saklofske, Wood, Eastabrook and Taylor (2005) have shown that there is evidence to suggest that student EI levels increase over a three-year period at university without participating in any specific EI intervention. However, if equal validity threats are assumed to have affected both groups, the following two observations can be drawn from the results. Firstly, the magnitude of change in pre to first post-test assessments was larger for the experimental than the control group. Secondly, although the groups obtained fairly similar pre-test baseline scores, the experimental group's second post-test EI levels were significantly higher than those of the control group $(p=0.037)$. This suggests that the development intervention partially succeeded in its objective of increasing the EI of the students in the experimental group, over approximately three months. These findings are in line with previous research (Burger, 2009; Görgens-Ekermans \& Swart, 2011; Nelis et al., 2009; Slaski \& Cartwright, 2003), and suggest that EI may be a rather malleable construct that could be enhanced.

It was hypothesised, secondly, that affect balance scores would increase after participation in the intervention. Taking into consideration the limitations of the results (i.e. total effect for the group-by-time interaction was non-significant), some tentative conclusions could be derived from the trends observed in the data. For example, whilst only negligible fluctuations were observed in control group scores, there was a significant mean score increase from the pre to first post-test assessment for the experimental group, with a notable drop in affect balance scores at the second post-test assessment (non-significant), suggesting only a temporary effect of the intervention. Affect balance scores were derived from the SPANE measurement (Diener, et al., 2009, 2010) which '... reflects a range of feelings ... The SPANE refers to the time people experience feelings ...' (Diener et al., 2010, p. 153). Diener, Suh, Lucas and Smith (1999) argue that our emotional systems react most strongly to new events and that these reactions diminish over time. Therefore, it could be argued that when affect balance and subjective feelings of well-being are considered, recent events usually have a greater impact on assessment measures. Furthermore, according to Diener et al. (1999), stress has a disproportionately large impact on an individual's feelings of subjective well-being and affect balance. Accordingly, it could be argued that the approaching and stressful mid-year exam (close to the second post-test measurement) might have influenced the participants' affective states, causing them to recall only recent events (which were mostly negative, resulting from the exam) when completing the assessment, so contributing to lower affect balance scores. Future research should address this limitation of the results by attempting to better control for external factors that introduce such validity threats to the data. 
The results revealed significant empirical support for the third hypothesis, that ASE would increase after exposure to the intervention. Empirical evidence supports the association between EI and self-efficacy (e.g. Hashemi \& Ghanizadeh, 2011). Although no previous studies, to the knowledge of the authors, have investigated whether or not self-efficacy could indirectly be increased through exposure to an EI intervention, some theoretical explanations could account for this favourable finding. According to self-efficacy theory, self-efficacy beliefs are, partially, formulated from affective states (Bandura, 1997, 2001). For example, positive affective states are interpreted as signs of proficiency in various life domains (Bandura, 1997), as mood states can bias attention and affect how events are interpreted (Bower, 1981). Positive moods, therefore, enhance perceived self-efficacy, whilst negative moods diminish it (Kavanagh \& Bower, 1985). EI research supports the notion that individuals with higher EI have the propensity to experience fewer negative emotions and more positive emotions, so contributing to a better sense of well-being (Kafetsios \& Zampetakis, 2008). The results would seem to suggest that the development of EI could affect ASE, possibly resulting from increasing emotionalregulation skills (e.g. emotional management and control) contributing to enhanced self-efficacy. An elevation in affect balance scores (as observed at the first post-test assessment) could have been the result of better emotional-regulation EI skills, which could also have influenced this result. However, it is argued that the more stable and trait-like nature of the EI regulation skills could have contributed to the longevity of the ASE results as opposed to the affect balance results. More research is needed to understand the mechanisms through which elevated EI influence ASE. This result, however, is of practical importance for various reasons. Research has shown that self-efficacy is an important predictor of academic motivation and engagement (Prat-Sala \& Redford, 2010; Zimmerman, 2001), assists in dealing with test anxiety (Zimmerman, 2001) and adjustment to university life (Brady-Amoon \& Fuertes, 2011; Bryde \& Milburn, 1990; Chemers et al., 2001), whilst also predicting better academic performance and achievement (Elias \& MacDonald, 2007; Multon et al., 1991). The elevation of ASE through an EI intervention could, therefore, hold multiple benefits for students, which should translate into better chances of sustained success.

It was, fourthly, hypothesised that CTPS (visualising success, self-talk, and evaluating beliefs and assumptions) as components of ASL, would be affected by elevated EI. CTPS involves the creation and maintenance of functional patterns of habitual thinking (Manz, 1992; Manz \& Neck, 1999) that assist in the self-direction and self-motivation needed for effective performance (Manz, 1992; Neck \& Houghton, 2006; Neck \& Manz, 2010). Emotions influence our cognitive processes and behaviour. Depape et al., (2006), for example, showed that the CTPS sub-dimension of self-talk and EI are positively related. To this end, the emotional management and control strategies included in the EI intervention programme covered cognitive reappraisal strategies, identifying irrational beliefs, common thinking errors, and also emotional disputation and distraction techniques, with the aim of impacting on CTPS. The findings revealed that the group-by-time effect for CTPS was non-significant. However, the trends in the data did suggest some limited effect on the CTPS of the experimental group (e.g. significant increase from pre to first post-test assessment), which was not observed in the control group. Resulting from the possible effects of self-selection (Babbie \& Mouton, 2010), the experimental group started out with somewhat lower levels of CTPS than the control group. However, the results at the second post-test assessment suggested that near to similar levels were evident in both groups at the end of the threemonth period. Although the results suggested that enhancing CTPS (as a component of ASL) through an EI intervention was, strictly speaking, not empirically proven, it would seem that the experimental group participants may have benefitted somewhat from the intervention. This finding, however, requires supplementary empirical investigation.

The health-enhancing benefits of EI have strong empirical support as evidenced by a relatively recent meta-analysis by Martins, Ramalho and Morin (2010). Previous research on this particular EI developmental intervention has provided strong evidence that perceived stress is affected by an increase in EI (Gardner, 2005; Görgens-Ekermans \& Swart, 2011). It was, therefore, hypothesised (Hypothesis 5) that perceived-stress scores would decrease following participation in the EI development intervention. The results, however, did not replicate previous research in this regard (i.e. group-by-time effect was non-significant). That said, some notable observations could be drawn from the results. Firstly, fairly similar baseline stress levels were observed for both groups at the first pre-test assessment, although the two groups were quite diverse in terms of programme registrations over the two faculties (e.g. business management, engineering, molecular biology and biochemistry, human life sciences). This possibly highlights the notable impact of more generic non-academic stressors (Bryde \& Milburn, 1990) on perceived stress faced by all students. Secondly, the magnitude of decreased perceived stress levels was greater in the experimental, than group control group at the first post-test assessment. If equal validity threats (e.g. history, Babbie \& Mouton, 2010) are assumed for the two groups, then this result could suggest that the intervention may have had some limited effect on the experimental group. Thirdly, although both groups reported non-significant increases in perceived stress levels at the second post-test assessment (possibly resulting from the timing of the assessment being close to the mid-year exams), the final reported decreased stress levels over the threemonth period for the experimental group were significantly lower than their baseline starting level. This trend was not reflected in the control-group scores. Taken together, these last two observations could be interpreted as suggesting that the intervention may have had some limited effect, in terms of increasing EI and assisting experimental group students to reap the buffering effects thereof on their self-reported stress levels. However, a replication is needed in this regard. 
Various limitations to this study should be noted. Most notably, the two group non-equivalent design that was utilised is known to be especially susceptible to the internal validity threat of selection bias. The possible effect of this, and also various other internal validity threats (history, maturation, test-retesting, and compensatory rivalry, Babbie \& Mouton, 2010; Goldstein, 1993) were highlighted throughout the discussion of the results. According to Cook and Campbell (1979) the size and direction of some biases will be unknown in social science studies that do not employ randomisation, and, therefore, the conclusions derived in this study should be regarded as tentative. Moreover, the relatively high dropout rate of participants, and, therefore, the smaller sample size of the different groups, could have affected the statistical power of the experiment (Howell, 2004). Apart from this effect, this validity threat of experimental mortality (Babbie \& Mouton, 2010) could produce biased results, as only interested participants remained in the experiment. Lastly, the use of self-report measures in this study increases the problem of common-method variance, which could have affected the results.

A replication of this study on a larger sample - with better control of the mentioned internal validity threats - is advised. Future studies should also attempt to investigate the bidirectional effects between self-leadership, positive affect, and EI in more detail, and also test the role of positive affect as a mediating variable between EI and the other outcome variables. Future studies should also incorporate measures of academic achievement as indicative of student success. Lastly, further research that aims to uncover the dynamics of the psychological processes underlying sustained student success, based on the variables included in this study, should ideally utilise multivariate longitudinal models (e.g. latent growth models via structural equation modelling) to derive such research results.

In conclusion, the results of this study lay a foundation that suggest EI could be malleable and influence academic selfefficacy. More research is necessary regarding supplementary teaching and learning initiatives, such as EI development programmes, focused on non-cognitive personal resources, which are complementary to the academic offering at tertiary institutions, with the expectation of increasing student success rates.

\section{Acknowledgements Competing interests}

The authors declare that they have no financial or personal relationships which may have inappropriately influenced them in writing this article.

\section{Authors' contributions}

G.G-E. (Stellenbosch University) was responsible for the conceptualisation of the research, article write-up, data gathering. M.D. (Stellenbosch University) was responsible for the data gathering, original write-up in thesis, and R.d.P. (Stellenbosch University) helped with the article write-up.

\section{References}

Abe, J.A. (2011). Positive emotions, emotional intelligence, and successful experiential learning. Personality and Individual Differences, 51, 817-822. http://dx.doi. org/10.1016/j.paid.2011.07.004

Babbie, E., \& Mouton, J. (2010). The practice of social research (South African edn.) Cape Town: Oxford University Press.

Bandura, A. (1993). Perceived self-efficacy in cognitive development and functioning. Educational Psychologist, 28, 117-148. http://dx.doi.org/10.1207/ s15326985ep2802_3

Bandura, A. (1997). Self-efficacy: The exercise of control. New York: Freeman and Company.

Bandura, A. (2001). Social cognitive theory: An agentic perspective. Annual Review of Psychology, 52, 1-26. http://dx.doi.org/10.1146/annurev.psych.52.1.1

Boss, A.D., \& Sims, H.P. (2008). Everyone fails! Using emotional regulation and selfleadership for recovery. Journal of Managerial Psychology, 23, 135-150. http:// dx.doi.org/10.1108/02683940810850781

Bower, G.H. (1981). Mood and memory. American Psychologist, 36, 129-148. http:// dx.doi.org/10.1037/0003-066X.36.2.129

Brady-Amoon, P., \& Fuertes, J.N. (2011). Self-efficacy, Self-rated abilities, adjustment and academic performance. Journal of Counselling and Development, 89, 431-438. http://dx.doi.org/10.1002/j.1556-6676.2011.tb02840.x

Bryde, J.F., \& Milburn, C.M. (1990). Helping to make the transition from high school to college. In R.L. Emans (Ed.), Understanding undergraduate education (pp. 203-213). Vermillon, SD: University of South Dakota Press.

Burger, R. (2011). Elaboration and empirical evaluation of the De Goede learning potential structural model. Published master's thesis, University of Stellenbosch, Cape Town, South Africa.

Burger, T. (2009). Emotional intelligence and well-being in teachers. Master's thesis, University of Stellenbosch, Cape Town, South Africa.

Campbell, D., \& Stanley, J. (1963). Experimental and quasi-experimental designs for research. Chicago: Rand McNally. http://dx.doi.org/10.1037/0022-0663.93.1.55

Carver, C.S., Pozo, C., Harris, S.D., Noriega, V., Scheier, M., Robinson, D., et al. (1993). How coping mediates the effect of optimism on distress: A study of women with early stage breast cancer. Journal of Personality and Social Psychology, 65, 375-390. http://dx.doi.org/10.1037/0022-3514.65.2.375

Chambel, M.J., \& Curral, L. (2005). Stress in academic life: Work characteristics as predictors of student well-being and performance. Applied Psychology: An International Review, 54, 135-147. http://dx.doi.org/10.1111/j.1464-0597. 2005.00200.x

Chang, K.B.T. (2007). Can we teach emotional intelligence? Dissertation Abstract International Section A: Humanities and Social Sciences 67(12-A), 4451.

Chemers, M.M., Hu, L., \& Garcia, B.F. (2001). Academic self-efficacy and first-year college student performance and adjustment. Journal of Educational Psychology, 93, 55-64. http://dx.doi.org/10.1037/0022-0663.93.1.55

Chow, H.P. (2007). Psychological well-being and scholastic achievement among university students in a Canadian Prairie city. Social Psychology and Education, 10 483-493. http://dx.doi.org/10.1007/s11218-007-9026-y

Cohen, S., Kamarck, T., \& Mermelstein, R. (1983). A global measure of perceived stress. Journal of Health and Social Behavior, 24(4), 385-396. http://dx.doi. org/10.2307/2136404

Cook, T.D., \& Campbell, D.T. (1979). Quasi-experimentation: Design and analysis issues for field settings. Boston: Houghton Mifflin Company.

Depape, A.R., Hakim-Larson, J., Voelker, S., Page, S., \& Jackson, D.L. (2006). Self-talk and emotional intelligence in university students. Canadian Journal of Behavioural Science, 38, 250-260. http://dx.doi.org/10.1037/cjbs2006012

Diener, E., \& Fujita, F. (1995). Resources, personal strivings, and subjective wellbeing: A nomothetic and idiographic approach. Journal of Personality and Socia Psychology, 68, 926-935. http://dx.doi.org/10.1037/0022-3514.68.5.926

Diener, E., \& Seligman, M.E. (2002). Very happy people. Psychological Science, 13(1), 81-84. http://dx.doi.org/10.1111/1467-9280.00415

Diener, E., Suh, E.M., Lucas, R.E., \& Smith, H.L. (1999). Subjective well-being: Three decades of progress. Psychological Bulletin, 125(2), 276-302.

Diener, E., Wirtz, D., Tov, W., Kim-Prieto, C., Choi, D., Oishi, S., et al. (2009). New measures of well-being: Flourishing and positive and negative feelings. Social Indicators Research, 39, 247-266. http://dx.doi.org/10.1007/978-90-481-23544_12

Diener, E., Wirtz, D., Tov, W., Kim-Prieto, C., Choi, D., Oishi, S., et al. (2010). New well-being measures: Short scales to assess flourishing and positive and negative feelings. Social Indicators Research, 97(2), 143-156. http://dx.doi.org/10.1007/ s11205-009-9493-y

D'Intino, R.S., Goldsby, M.G., Houghton, J.D., \& Neck, C.P. (2007). Self-leadership: A process for entrepreneurial success. Journal of Leadership and Organisationa Studies, 13, 105-120. http://dx.doi.org/10.1177/10717919070130040101

Eastabrook, J.M., Duncan, A., \& Eldridge, B. (2005). Academic success in elementary school: Does El matter? Paper presented at the annual meeting of the Canadian Psychological Association, Montreal, QC. 
Ekermans, G., Burger, T., Swart, E., Saklofske, D., \& Poole, J. (2010). Transferring an emotional intelligence intervention for teachers from a developed to a developing country: A Canadian and South African comparison Paper presented developing country: A Canadian and South African comparison. Paper presented Winnipeg.

Elias, S.M., \& MacDonald, S. (2007). Using past performance, proxy efficacy and academic self-efficacy to predict college performance. Journal of Applied Social Psychology, 37(11), 2518-2531. http://dx.doi.org/10.1111/j.15591816.2007.00268.x

Entwistle, N., \& Tait, H. (1990). Approaches to learning, evaluation of teaching and preferences for contrasting academic environments. Higher Education, 19, 169-194. http://dx.doi.org/10.1007/BF00137106

Fletcher, L., Leadbetter, P., Curran, A., \& O'Sullivan, H. (2009). A pilot study assessing emotional intelligence training and communication skills with $3 \mathrm{rd}$ year medical students. Patient Education and Counselling, 76, 376-379. http://dx.doi. org/10.1016/j.pec.2009.07.019

Fredrickson, B.L. (2004). The broaden-and-build theory of positive emotions. The Royal Society, 359, 1367-1377. http://dx.doi.org/10.1098/rstb.2004.1512

Fredrickson, B.L., \& Joiner, T. (2002). Positive emotions trigger upward spirals towards emotional well-being. Psychological Science, 13(2), 172-175. http://dx.doi org/10.1111/1467-9280.00431

Fredrickson, B.L., \& Losada, M.F. (2005). Positive affect and the complex dynamics of human flourishing. American Psychologist, 60(7), 678-686. http://dx.doi. org/10.1037/0003-066X.60.7.678

Gardner, L. (2005). Emotional intelligence and occupational stress. PhD dissertation, Swinburne University of Technology, Melbourne, Australia.

Ghiselli, E.E., Campbell, J.P., \& Zedek, S. (1981). Measurement theory for the behavioural sciences. New York: W. H. Freeman.

Goldsmith, D., \& Albretech, T. (1993). The impact of supportive communication networks on test anxiety and performance. Communication Education, 6, 142-158. http://dx.doi.org/10.1080/03634529309378921

Goldstein, I.L. (1993). Training in organisations: Needs assessment, development and evaluation (3rd edn.). Belmont, CA: Thomas Brooks/Cole Publishing Company.

Goldstein, I.L., \& Ford, J.K. (2001). Training in organizations: A needs assessment, development, and evaluation. Belmont, CA: Wadsworth.

Görgens-Ekermans, G., \& Brand, T. (2012). Emotional intelligence as a moderator in the stress-burnout relationship: A questionnaire study on nurses. Journal in the stress-burnout relationship: A questionnaire study on nurses. Journal of Clinical Nurs

Görgens-Ekermans, G., \& Herbert, M. (2013). Psychological capital: Internal and external validity of the Psychological Capital Questionnaire (PCQ-24) on a South African sample. SA Journal of Industrial Psychology/SA Tydskrifvir Bedryfsielkunde, 39(2), 12. http://dx.doi.org/10.4102/sajip.v39i2.1131

Görgens-Ekermans, G. \& Swart, E. (2011). Developing emotional intelligence for increased stress management and better psychological and physical health Data from two studies. Paper presented at the 15th Biennial Meeting of the Data from two studies. Paper presented at the 15th Biennial Meeting of the
International Society for the Study of Individual differences (ISSID), 25-28 July, International
London, UK.

Grosman, F.M., \& Johnson, K.M. (1982). WISC-R factor scores as predictors of WRAT performance: A multivariate analysis. Psychology in the Schools, 19, 465-468. http://dx.doi.org/10.1002/1520-6807(198210)19:4\%3C465::AIDPITS2310190409\%3E3.0.CO;2-J

Hashemi, M.R., \& Ghanizadeh, A. (2011). Emotional intelligence and self-efficacy: A case of Iranian EFL University students. International Journal of Linguistics, 3(1) E29. http://dx.doi.org/10.5296/ijl.v3i1.877

Hen, M., \& Goroshit, M. (2012). Academic procrastination, emotional intelligence, academic self-efficacy, and GPA: A comparison between students with and without learning disabilities. Journal of Learning Disabilities.

Herman, C. (2012). Developing emotional intelligence for increased work engagement organisational commitment, and satisfaction with work life. Unpublished master's thesis, University of Stellenbosch, Cape Town, South Africa.

Higher Education South Africa. (2012). Annual report 2012. Retrieved from http:// www.hesa.org.za/hesa $\%$ E2\% $\% 0 \% 99$ s-annual-report-2012-published

Hobfoll, S.E. (1989). Conservation of resources: A new attempt to conceptualizing stress. American Psychologist, 44(3), 531-524. http://dx.doi.org/10.1037/0003066X.44.3.513

Hobfoll, S.E. (2001). The influence of culture, community, and the nested-self in the stress process: Advancing conservation of resources theory. Applied Psychology: An stress process: Advancing conservation of resources theory. Applied Psychology: An
International Review, 50(3), 337-421. http://dx.doi.org/10.1111/1464-0597.00062

Houghton, J.D., \& Neck, C.P. (2002). The revised self-leadership questionnaire: Testing a hierarchical factor structure for self-leadership. Journal of Managerial Psychology, 17(8), 672-691. http://dx.doi.org/10.1108/02683940210450484

Howell, D.C. (2004). Fundamental statistics for the behavioural sciences (5th edn.). Belmont, CA: Thompson Learning.

Kafetsios, K., \& Zampetakis, L.A. (2008). Emotional intelligence and job satisfaction: Testing the mediatory role of positive and negative affect at work. Personality and Individual Differences, 44, 712-722. http://dx.doi.org/10.1016/j.paid.2007.10.004

Kavanagh, D.J., \& Bower, G.H. (1985). Mood and self-efficacy: Impact of joy and sadness on perceived capabilities. Cognitive Therapy and Research, 9, 507-525. http://dx.doi.org/10.1007/BF01173005

Keefer, K.V., Parker, J.D., \& Wood, L.M. (2012). Trait emotional intelligence and university graduation outcomes: Using latent profile analysis to identify students at risk for degree non-completion. Journal of Psychoeducational Assessment, 30(4), 102-413. http://dx.doi.org/10.1177/0734282912449446
Lent, R.W., Brown, S.D., \& Larkin, K.C. (1984). Relationship of self-efficacy expectations to academic achievement and persistence. Journal of Counselling Psychology, 31 356-362. http://dx.doi.org/10.1037/0022-0167.31.3.356

Lucas, R.E., Diener, E., \& Suh, E.M. (1996). Discriminant validity of well-being measures. Journal of Personality and Social Psychology, 71, 616-628. http://dx.doi.org/10.1037/0022-3514.71.3.616

Luebbers, S., Downey, L.A., \& Stough, C. (2007). The development of an adolescent measure of El. Personality and Individual Differences, 42, 999-1009. http://dx.doi. org/10.1016/j.paid.2006.09.009

Lyubomirsky, S., King, L., \& Diener, E. (2005). The benefits of frequent positive affect: Does happiness lead to success? Psychological Bulletin, 131(6), 803-855. http://dx.doi.org/10.1037/0033-2909.131.6.803

Mabelebele, J. (2012). Towards strengthening HESA-NASDEV partnerships: Some tentative views. Johannesburg: Higher Education South Africa.

Manz, C.C. (1992). Mastering self-leadership: Empowering yourself for personal excellence. Englewood Cliffs, NJ: Prentice-Hall.

Manz, C.C., \& Neck, C.P. (1999). Mastering self-leadership: Empowering yourself for personal excellence (2nd edn.). Upper Saddle River, NJ: Prentice-Hall.

Martins, A., Ramalho, N., \& Morin, E. (2010). A comprehensive meta-analysis of the relationship between emotional intelligence and health. Personality and Individual Differences, 49(6), 554-564. http://dx.doi.org/10.1016/j.paid.2010.05.029

Mayer, J.D., \& Salovey, P. (1997). What is emotional intelligence? In P. Salovey, \& D. Sluyter, Emotional development and emotional intelligence: Implications for educators (pp. 3-31). New York: Basic Books Inc.

Mayer, J.D., Salovey, P., \& Caruso, D. (2000). Emotional Intelligence as a zeitgeist, as personality and as mental ability. In R. Bar-On \& J.D. Parker (Eds.), The Handbook of emotional intelligence (pp. 3-31). San Francisco, CA: Jossey-Bass.

Multon, K.D., Brown, S.D., \& Lent, R.W. (1991). Relationship of self-efficacy beliefs to academic outcomes: A meta-analytic investigation. Journal of Counselling Psychology, 18, 30-38. http://dx.doi.org/10.1037/0022-0167.38.1.30

Neck, C.P., \& Houghton, J. D. (2006). Two decades of self-leadership theory and research: Past developments, present trends, and future possibilities. Journal of Management Psychology, 21, 270-295.

Neck, C.P., \& Manz, C.C. (1996). Thought self-leadership: The impact of mental strategies training on employee behaviour, cognition, and emotion. Journal of Organisational Behaviour, 17, 445-467. http://dx.doi.org/10.1108/02683940610663097

Neck, C.P., \& Manz, C.C. (2010). Mastering self-leadership: Empowering yourself for personal excellence (5th edn.). New Jersey: Prentice-Hall.

Neisser, U., Boodoo, G., Bouchard, T.I., Boykin, A.W., Brody, N., Ceci, S.J., et al. (1996) Intelligence: Knowns and unknowns. American Psychologist, 51, 77-101. http:// dx.doi.org/10.1037/0003-066X.51.2.77

Nelis, D., Quoidbach, J., Mikolajczak, M., \& Hansenne, M. (2009). Increasing emotional intelligence: (How) is it possible? Personality and Individual Differences, 47, 3641. http://dx.doi.org/10.1016/j.paid.2009.01.046

Norris, S.E. (2008). An examination of self-leadership. Emerging Leadership Journeys, $1(2), 43-61$.

Nunnally, J.C., \& Bernstein, I.H. (1994). Psychometric theory (3rd edn.). New York: McGraw-Hill.

Ojeda, L., Flores, L.Y., \& Navarro, R.L. (2011). Social cognitive predictors of Mexican American college students' academic and life satisfaction. Journal of Counselling Psychology, 58, 61-71. http://dx.doi.org/10.1037/a0021687

Palmer, B.R., \& Stough, C. (2001). Workplace SUEIT: Swinburne University emotional intelligence test-technical manual. Organisational Psychology Research Unit, Australia.

Pancer, S.M., Hunsberger, B., Pratt, M.W., \& Alisat, S. (2000). Cognitive complexity of expectations and adjustment to university in the first year. Journal of Adolescent Research, 15, 38-57. http://dx.doi.org/10.1177/0743558400151003

Parker, J.D., Hogan, M.J., Eastabrook, J.M., Oke, A., \& Wood, L.M. (2006). Emotional intelligence and student retention: Predicting the successful transition from high school to university. Personality and Individual Differences, 41, 1329-1336. http://dx.doi.org/10.1016/j.paid.2006.04.022

Parker, J.D., Saklofske, D.H., Wood, L.M., Eastabrook, J.M., \& Taylor, R.N. (2005). Stability and change in emotional intelligence: Examining the transition to young adulthood. Journal of Individual Differences, 26, 100-106. http://dx.doi. org/10.1027/1614-0001.26.2.100

Parker, J.D., Summerfeldt, L.J., Hogan, M.J., \& Majeski, S.A. (2004). Emotional intelligence and academic success: Examining the transition from high school to university. Personality and Individual Differences, 36, 163-172. http://dx.doi. org/10.1016/S0191-8869(03)00076-X

Prat-Sala, M., \& Redford, P. (2010). The interplay between motivation, self-efficacy and approaches to studying. Journal of Educational Psychology, 80, 238-305. http://dx.doi.org/10.1348/000709909x480563

Seligman, M.E., \& Csikszentmihalyi, M. (2000). Positive psychology. American Psychologist, 55, 5-14. http://dx.doi.org/10.1037/0003-066X.55.1.5

Slaski, M., \& Cartwright, S. (2003). Emotional intelligence training and its implications for stress, health and performance. Stress and Health, 19, 233-239. http://dx.doi. org/10.1002/smi.979

Sparkman, L.A., Maulding, W.S., \& Roberts, J.G. (2012). Non-cognitive predictors of student success in college. College Student Journal, 46(3), 642-652.

Spaull, N. (2013). South Africa's education crisis: The quality of education in South Africa 1994-2011. Centre for Development and Enterprise. 
StatSoft, Inc. (2012). STATISTICA (data analysis software system), version 11. Retrieved from www.statsoft.com

Staw, B.M., Sutton, R.I., \& Pelled, L.H. (1994). Employee positive emotions and favourable outcomes at the workplace. Organisational Sciences, 5, 51-71. http://dx.doi.org/10.1287/orsc.5.1.51

Stein, S. J., \& Book, H. E. (2011). The EQ edge. Canada: John Wiley \& Sons.

Vandervoort, D.J. (2006). The importance of emotional intelligence in higher education. Current Psychology: Developmental, Learning, Personality, Social, 25, 4-7. http://dx.doi.org/10.1007/s12144-006-1011-7

West, B.T., Welch, K.B., \& Galecki, A.T. (2007). Linear mixed models: a practical guide using statistical software. CRC Press.
Wood, L.M., Zohar, A., Bates, K., \& Parker, J.D. (2006). Enhancing El in post-secondary students: Impact of a first year business management course. Poster Presented at annual meeting of the Canadian Psychological Association, Calgary, Alberta.

Yorke, M., \& Longden, B. (2005). Setting the Scene. In M. Yorke \& B. Longden (Eds.) Retention and student success in higher education (pp. 4-12). Maidenhead: Open University Press.

Zimmerman, B. (1989). A social cognitive view of self-regulated academic learning. Journal of Educational Psychology, 81, 329-339. http://dx.doi.org/10.1037/0022 0663.81.3.329

Zimmerman, B.J. (2001). Self-efficacy and educational development. In A. Bandura (Ed.), Self-efficacy in changing societies (pp. 202-231). Melbourne: Cambridge University Press. 